\title{
A FOSSIL PETRIFIED DICOTYLEDONOUS LEAF XEROPHYLLUMINTERTRAPPEA FROM DECCAN INTERTRAPPEAN BEDS OF INDIA
}

\author{
Puranik S.D. \\ Shivaji science college, nagpur \\ sumedhadpuranik@gmail.com
}

\begin{abstract}
The fossil dicotyledonous leaf collected from Mohgaonkalan. The fossil leaf dicotylednous, dorsiventral, hypostomatic leaf. Mesophyll differentiated into palisade parenchyma and spongy parenchyma. Single layered upper and lower epidermis, single layered hypodermis, clustered crystal like bodies present in mesophyll, bicolateral vascular strand in midrib region, collateral and conjoint in veinlet bundle, canals in mesophyll, stomata on lower surface of the leaf present in pit cavity with unicellular hairs.Veinlets bundle conjoint and collateral. The fossil leaf under discussion shows many characters of Apocyanaceae with close approach to genus Nerium of Apocyanaceae. But it does resemble Nerium in sensustricto. As it shows xerophytic characters it is named as Xerophyllumintertrappea gen. et. sp. nov.; the generic name is being after xerophytic characters and specific name is being after beds.

Keywords: Petrified leaf, dicotyledonous, mesophyll, canal, conjoint, collateral, bicolateral, pit cavity.
\end{abstract}

\section{INTRODUCTION:}

The present paper deals with the dicotyledonous leaf from the Deccan Intertrappean series of Mohgaonkalan(Lat. 22 1' $0^{\prime \prime} \mathrm{N}$; Long. 79 11' 18"E) Chhindwara district M.P., India. Only one Apocynaceous wood has been reported from this locality by Patki (1986) as Tabernaemontana mohgaoensis. So far many dicotyledonous leaves have been reported from this locality but the present leaf is the first record of Apocyanaceous leaf from the same locality.

\section{MATERIAL AND METHOD:}

The material was collected from Mohgaonkalan, dist. Chhindwara, M.P. The specimen is in the form of a long strip with prominent midrib portion which can be seen with naked eye after itching. The material is studied by taking peel section along transverse plane only.

Description: The leaf is dorsiventral swollen in midrib portion with two arms (Plate. 1, fig. 1). One arm of the leaf is completely preserved while the other arm is incompletely preserved. The leaf measure $18 \mathrm{~mm}$ in width. One laminar arm measures $12 \mathrm{~mm}$ in width while incomplete arm $5 \mathrm{~mm}$ in width and midrib region measure $1 \mathrm{~mm}$ in width. The leaf measure $928 \mu$ in thickness in the region of median vascular bundle, while laminar arms measure $214 \mu$ in thickness. Laminar arms are uniform in thickness expect at vein let vascular bundle where it measures 270 $470 \mu$ in thickness. (Plate. 1 fig. 1). The under investigation is thick and leathery with well developed cuticle and hair in pit cavity (Plate 2 . Fig. 4,5). The upper epidermis is well preserved. It is single layered with more or less barrel shaped parenchymatous cells. The upper epidermis id divoid of stomata and other out growths. The cells of epidermis are compactly arranged with very thick cuticle. Cuticle is displaced at some places (plate 1. Fig. 5). Epidermis is followed by single layered hypodermis. The cells of hypodermis are squarish to rectangular and epithelial cells with contents which are parenchyamatous in nature. These canals measure $62 \mu$ in diameter spongy parenchyma is followed by lower epidermis with thick cuticle (Plate.1,Fig.2). It is single layered consisting of barrel shaped parenchyamtous cells. On lower epidermis large pits are present in which stomata are observed (Plate.2. Fig. 4 \& 5). However the structure of stomata cannot be studied due to ill- preservation. But this pit show presence of unicellular hairs. So the nature of stomata might be sunken? Hair measures $11 \mu$ in length. Hairs are preserved only at some places (Plate. 2,Fig. 4,5). There is a single median vascular bundle with bundle sheath (Plate 1, Fig. $2,3)$. In this region epidermis is followed by 7-8 layered compactly arranged parenchyamatous cells with contents (Plate. 1, Fig. 2,3). They are most compact then laminar region. Vascularbundle is crescent shaped by co-lateral (Plate 1, Fig. 2,3). The arrangement of xylem is $\mathrm{v}$ shaped with metaxylem and proto-xylem. Metaxylem is present towards the lower epidermis (Plate. 1, Fig. 2,3) while protoxylem elements are towards the upper epidermis. Metaxylem elements measure 39-46 $\mu$ in diameter. In oblique section, Metaxylem shows spiral thicknening, protoxylem elements measure $7-14 \mu$ in diameter. These are not well measured. The phloem is present on both sides i.e, towards upper $\mathrm{n}$ lower faces of the xylem (Plate. 1, Fig. 2,3). Phloem is 
well preserved at places. Cells of the phloem are somewhat squarished to spherical in shaped. Bundle sheath surrounds vascular bundle which is 1-2 layered. Cells of the bundle sheath are thick walled parenchyamatous in nature. The vascular strands of lateral veins are seen in laminar wings. These are conjoint, collateral. They show 5-7 xylem elements with parenchyamtous sheath. The smaller veinlet bundle measures 270- $285 \mu$ while larger veinlet bundle 380- $470 \mu$ in thickness. Xylem elements shows spiral thickenings. In oblique sections. Phloem is present towards the lower epidermis (Plate 1, Fig. 2,3). Cells of phloem are thin walled. However details of phloem cannot be seen because of ill preservation.

\section{DISCUSSION :}

The important anatomical characters of this leaf are as follows-

- Presence of thick cuticle on both surfaces. Upper cuticle is thicker than the lower.

- Presence of single layered upper and lower epidermis.

- Presence of hypodermis.

- Differentiation of mesophyll into palisade and spongy parenchyma.

- Presence of clustered crystal like bodies in the mesophyll.

- Single median vascular bundles which is bicollateral.

- Veinlet vascular bundles are conjoint and collateral.

- Presence of canals in the mesophyll tissue.

- Presence of stomata in the pit cavity showing unicellular hairs. (sunken in nature).

Above mentioned characters show that fossil leaf under consideration is dicotyledonous, dorsiventral and xerophytic in nature. Therefore it is compared with families like Asclepiadaceae and Apocypaceae. The present fossil leaf resembles the leaves of the family Asclepiadaceae in the following characters.

- Presence of thick cuticle.

- Single layered epidermis.

- Presence of hypodermis.

- Presence of unicellular hairs.

- Differentiation of mesophyll into palisade and spongy parenchyma.

- Nature of vascular bundle in midrib and veinlet region.

- Presence of canals (comparable with laticiferous canals)

- Presence of clustered crystals.

Present fossil differs from Asclepiadaceae in having stomatain pit cavity and absence of hair on upper epidermis. The comparison of fossil specimen with Apocynaceae shows following similarities.

1. Differentiation of mesophyll into palisade and spongy parenchyma.

2. Presence of unicellular hairs.

3. Presence of hypodermis.

4. Nature of vascular bundle of midrib. (In both bicolateral vascular strand is present).

5. Presence of canals (Asclepiadaceae, laticiferous canals are present).

6. Presence of clustered crystals in mesophyll.

The fossil shows similarities with genus Neriumof Apocynaceae in following characters:

1. Presence of cuticle.

2. Presence of hypodermis.

3. Nature of vascular bundle in midrib region (bicollateral) and in veinlet region (collateral).

4. Presence of clustered crystals in mesophyll.

5. Presence of canals.

6. Presence of stomata in the pit cavity on the lower side of leaf with hairs which are unicellular (i.e. Sunken stomata).

But in Nerium multiple epidermis is present on both sides of the leaf which is absent in the fossil leaf. In Nerium both upper and lower palisade parenchyma are present whereas in the present fossil leaf only upper palisade parenchyma is seen and lower palisade parenchyma is absent. Laticferous canals are present in vein region inNerium (Metcalfe and Chalk, 1950). In fossil leaf canals comparable with laticiferous canals are present in mesophyll. In Nerium hairs are present on upper epidermis while in present fossil specimen hairs are absent on upper epidermis. Thus it is evident that the leaf under discussion shows many characters of Apocyanaceae with close approach to genus Nerium of Apocyanaceae. But it does resemble Nerium in sensustricto. As it shows xerophytic characters it is named as Xerophyllumintertrappea gen. et. sp. nov.; the generic name is being after xerophytic characters and specific name is being after beds.

DIAGNOSIS: Xerophyllum gen. nov.

Dicotylednous, dorsiventral, hypostomatic leaf. Mesophyll differentiated into palisade parenchyma and spongy parenchyma. Single layered upper and lower epidermis, single layered hypodermis, clustered crystal like bodies present in mesophyll, bicolateral vascular strand in midrib region, colateral and conjoint in veinlet bundle, canals in mesophyll, stomata on lower surface of the leaf present in pit cavity with unicellular hairs.

Xerophylluminter trappea gen. et. sp. nov.

A leaf $18 \mathrm{~mm}$ in width and $214 \mu$ in thickness; cuticle present on both surfaces, epidermis single layered, single layered hypodermis, stomata in pit 
cavity present on lower side of the leaf with unicellular hairs. Hairs $11 \mu$. Mesophyll differentiated into 2-3 layered, palisade parenchyma and multilayered spongy parenchyma, cells of the palisade parenchyma 19 $\mu$ in length and $8 \mu$ in breadth. Clustered crystal like bodies present in cavity in mesophyll, 36-52 $\mu$ in diameter, canals present in spongy parenchyma, $62 \mu$ in diameter, vascular bundle single median and bicolateral, $928 \mu$ in thick, veinlets bundle conjoint andcolateral and 270 $470 \mu$ in thickness, metaxylem elements measures39-46 $\mu$ in T.S. diameter. Protoxylem elements measures $7-14 \mu$ in diameter.

Holotype: Departmentof Botany, Institute of Science, Nagpur.

Locality: Mohgaonkalan.

Horizon: Deccan Intertrapean Series of India. Age:? Palaeocene.

Xerophyllumintertrappea gen. et. sp. nov.

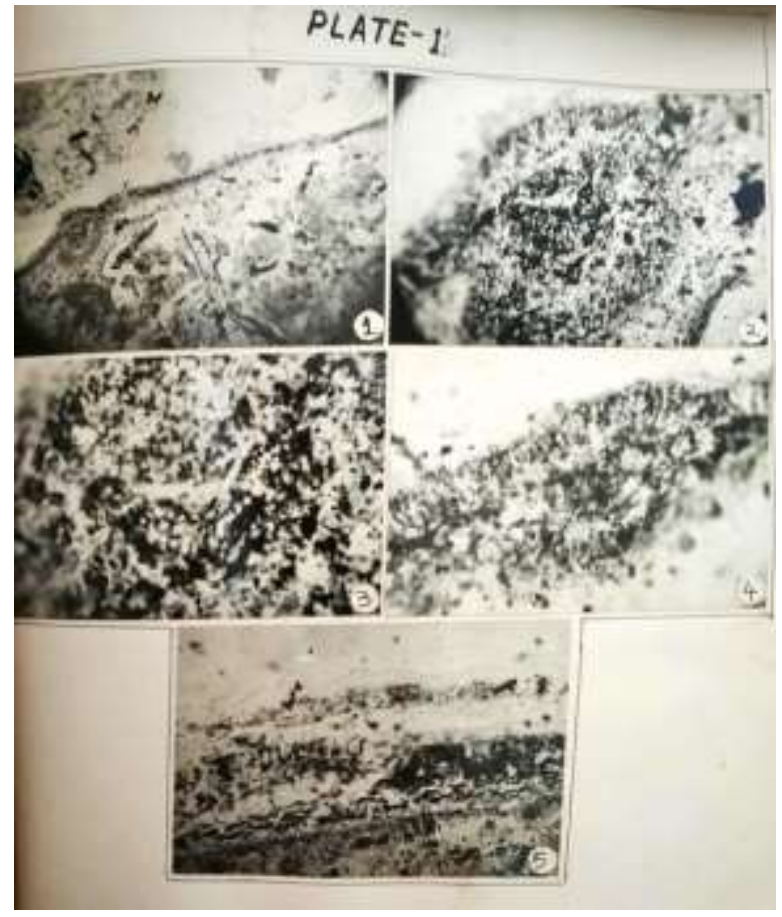

Explanation of Plate 1

- Fig. 1: T.S. leaf showing median vascular bundle and two laminar arms. X40

- Fig. 2: T.S.ofleaf showing median vascular bundle with xylem andpholem, phloem on both sides of the xylem. X 155

- Fig. 3: Median vascular bundle (magnified). X 300

- Fig. 4: T.S. of veinlet bundle showing conjoint, collateral condition. X 200

- Fig. 5: T.S. of leaf showing laminar region with thick cuticle (displaced), hypodermis, palisade

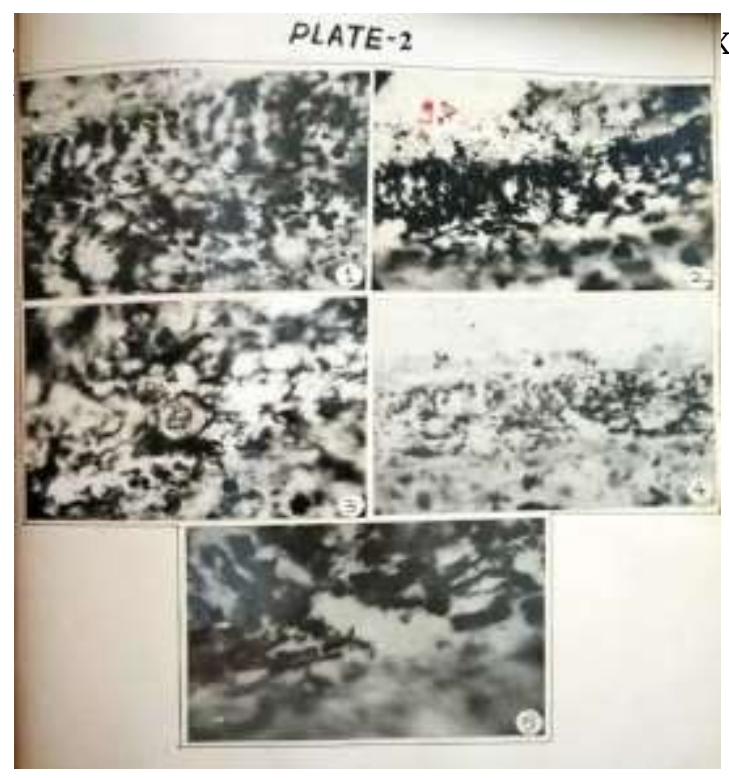

\section{Explanation of Plate 2}

- Fig. 1: T.S. leaf showing upper epidermis, hypodermis and mesophyll. X580

- Fig. 2: Mesophyll showing cavities with contents (arrow) X 300

- Fig. 3: Mesophyll showing cavities with clustered crystals (druses) (star shaped). X 580

- Fig. 4: T.S. lamina showing large pit cavity on lower epidermis and canal with epithelial cells in spongy parenchyma. (arrow) X 200

- Fig. 5: Magnified structure of pit cavity with unicellular hairs and stomata. X 750

\section{REFERENCES:}

Hislop S. (1853). Remarks on the geology of Nagpur. J. Bomb. Asiat. Soc. 5:58-67

Hislop S. (1854). Remarks on geology of Nagpur J. Geol.soc. London . 11:356.

Hislop S. and Hunter R. (1854). A sketch of the geology of Nagpur. Cuart. Jour. Geol. Soc. 10:470-473.

Hislop S. and Hunter R. (1855). On the geology and fossil of neighborhood of Nagpur, central India. Cuart. J. Geol.Soc. London. 11(3): 354-383.

Metcalfe, C. R and Chalk, L.(1950). Anatomy of the dicotyledonous I \& II Oxford university press Great Britain.

Patki, S.P. (1986). A Treatise on the Deccan Intertrappean plants. Ph.D. Thesis, Nagpur University, Nagpur.

Sahni B. (1934). Silicified flora of the Deccan series - Part II. Gymnospermous and Angiospermous fruits. Proc. 21 st Indian Sci. Cong. Bombay. Abst. 3: 317-318. 